\title{
PENSÃO POR MORTE - APLICAÇÃO DA MP № 871/2019 EM RELAÇÃO À UNIÃO ESTÁVEL
}

\section{ARTIGO ORIGINAL}

JUNIOR, Hamilton Roberto Santos ${ }^{1}$

GOUVEIA, Carlos Alberto Vieira de ${ }^{2}$

JUNIOR, Hamilton Roberto Santos. GOUVEIA, Carlos Alberto Vieira de. Pensão por morte - Aplicação da MP no 871/2019 em relação à união estável. Revista Científica Multidisciplinar Núcleo do Conhecimento. Ano 04, Ed. 07, Vol. 02, pp. 16-27. Julho de 2019. ISSN: 2448-0959

\section{RESUMO}

O objetivo desse artigo cientifico é apresentar a alteração implantada pela Medida Provisória no.: 871/2019, com o estudo e análise do seu art. 25, que inclui o parágrafo 5º, no artigo 16, da Lei 8.213/91, introduzindo o entendimento da Súmula no 63 , da Turma Nacional de Uniformização dos Juizados Especiais Federais - TNU: considerando a prova testemunhal insuficiente; a exigência de prova material e estipulação de prazo limite para requerimento da pensão por morte. Em particular aos dependentes por união estável, causando dificuldades que para a concessão dos benefícios a esses dependentes. Principalmente as dificuldades para a comprovação da situação de união estável com entidade familiar, tanto por meio de prova documental como por prova testemunhal e a expectativa de aumento nas lides previdenciárias, com o intuito de provar a situação de união estável, comprovando a constituição da entidade familiar. Por consequência, a afetação e verificação do

\footnotetext{
${ }_{1}^{1}$ Pós-graduando na Academia AJURÍDICA, advogado e Tecnólogo em Logística.

2 Diretor Acadêmico da Academia AJURÍDICA, Mestre em Ciências Ambientais, Doutorando em Ciências Sociais e Jurídicas, autor e advogado.
} 
afastamento do direito à Previdência Social do dependente companheiro em situação de união estável.

Palavras-chave: MP 871/19, pensão por morte, dependente por união estável.

\section{INTRODUÇÃO}

A MP 871/2019 do Presidente Jair Bolsonaro, assinada e publicada no Diário Oficial da União no dia 18 de janeiro de 2019, estabelece uma série de mudanças. Em síntese, a MP estabelece novas regras na concessão de alguns tipos de benefícios, bem como a revisão daqueles que existe alguma suspeita de irregularidades.

De forma generalizada a medida provisória é uma pré-reforma, um plano de ensaio, para a implantação do real e concreta reforma previdenciária que há de ser instaurada no pais. Esse artigo foca em estudar a aplicação da MP 871/2019, nas garantias previdenciárias dos dependentes, com ênfase nos dependentes por união estável.

Diante do cenário previdenciário nacional, setor esse, que a cada ano majora sua importância, devido a ampliação da expectativa de tempo de vida. Onde, segundos dados do IBGE, nos anos 2000, havia $8,2 \%$ (oito virgula dois por cento) da população brasileira era composta por idosos e há uma previsão de que em 2020, tornem-se $13,8 \%$ (treze virgula oito por cento), mantendo-se em uma crescente.

O objetivo desse artigo cientifico é apresentar a alteração implantada pela MP 871/2019, em seu art. 25, que inclui o parágrafo 5o, no artigo 16, da Lei 8.213/91, introduzindo o entendimento da Súmula ํㅡ 63, da Turma Nacional de Uniformização dos Juizados Especiais Federais - TNU: considerando a prova testemunhal insuficiente; a exigência de prova material e estipulação de prazo limite para requerimento da pensão por morte. Em particular aos dependentes por união estável, causando a esses, dificuldades que para a concessão dos benefícios a esses dependentes.

Os dependentes previdenciários por união estável, que fazem jus ao benefício de pensão por morte, em sua maioria são idosos, de baixa renda, com pouca saúde, sem 
autonomia, que vivem uma morte social. Dificultar a concessão do benefício aumentando os requisitos objetivos é ferir o direito fundamental da dignidade da pessoa humana.

Para a realização desse artigo científico foi utilizado os meios de pesquisa bibliográfica, através de leitura e estudo dos referenciais teóricos, legislações, publicações cientificas e livros. A pesquisa bibliográfica foi efetuada através do levantamento e seleção de documentos já publicados sobre as disposições da Medida Provisória número 871/2019, bem como dos direitos garantidos à união estável frente ao Direito Previdenciário.

Desse modo, o artigo científico comenta primeiramente o conceito de dependentes previdenciários, assim, demonstrando quem são atores objetos da pesquisa. No segundo capítulo apresentará a descrição do beneficiário companheiro e a situação de união estável, da mesma maneira que demonstrará os requisitos para sua comprovação. O terceiro capítulo caracteriza-se pelo estudo da aplicação da MP 871/2019 em relação aos direitos e garantias do dependente previdenciário em situação de união estável. Bem como as dificuldades para a comprovação da situação de união estável e a expectativa de aumento nas lides previdenciárias, com o intuito de provar a situação de união estável.

\section{DEPENDENTES PREVIDENCIÁRIOS}

Dependentes previdenciários são uma espécie de segurado, um possível beneficiário da previdência social. Segundo Castro e Lazzari (2017), os dependentes, ainda que não contribuinte para a Seguridade Social. Fazem jus as seguintes prestações: pensão por morte, auxílio reclusão, serviço social e reabilitação profissional. Pois, os dependentes previdenciários correspondem com os credores de alimentos da Lei Civil. Desse modo, mantém uma vinculação econômica com o segurado.

De acordo com o Professor Gouveia (2009), são também considerados segurados em modalidade especial, isto é, sem contribuição, pois são dependentes dos segurados, os quais segundo o ditame legal fazem jus aos benefícios de pensão por morte e 
auxílio reclusão. Porém é importante observar que não é qualquer dependente do segurado que será considerado dependente para fins previdenciários.

Conforme explicado acima, dependentes previdenciários nada mais são que os beneficiários indiretos, beneficiários que não contribuíram. Porem são dependentes dos segurados previdenciários e esses sim pagantes para fazer jus ao benefício previdenciário.

Os dependentes estão conjecturados no artigo 16 da Lei 8.213/91 e fracionados em três classes:

"Art. 16. São beneficiários do Regime Geral de Previdência Social, na condição de dependentes do segurado:

I - o cônjuge, a companheira, o companheiro e o filho não emancipado, de qualquer condição, menor de 21 (vinte e um) anos ou inválido;

II - os pais;

III - o irmão não emancipado, de qualquer condição, menor de 21 (vinte e um) anos ou inválido;

$\S 1^{\circ} \mathrm{A}$ existência de dependente de qualquer das classes deste artigo exclui do direito às prestações os das classes seguintes.

$\S 2^{\circ}$. O enteado e o menor tutelado equiparam-se a filho mediante declaração do segurado e desde que comprovada a dependência econômica na forma estabelecida no Regulamento.

§ 3ํㅡㄴ Considera-se companheira ou companheiro a pessoa que, sem ser casada, mantém união estável com o segurado ou com a segurada, de acordo com o $\S 3^{\circ}$ do art. 226 da Constituição Federal.

$\S 4^{\circ}$ A dependência econômica das pessoas indicadas no inciso I é presumida e a das demais deve ser comprovada". 
Ao analisar o artigo 16 da Lei da Previdência Social, Torres (2012), observa, "primeiramente, que a maioridade civil,18 anos, não coincide com a previdenciária, já que o filho e o irmão válidos mantêm a qualidade de dependentes até completarem 21 anos, desde que não se emancipem antes disso". Logo, o benefício da pensão por morte é percebido por filho, que não seja inválido ou emancipado, do segurado falecido até os 21 anos, não ocorrendo o término aos 18 anos.

O professor Carlos Gouveia apresenta os dois critérios estabelecidos pela legislação para o enquadramento do dependente do segurado como dependente previdenciário:

"Os critérios para estabelecer a dependência para fins previdenciários são dois: Econômico e Familiar. Sendo que no caso dos dependentes de primeira classe, a dependência econômica é presumida, já para as demais classes deve se demonstrar o critério familiar e a dependência econômica existente entre segurado e dependente, contudo, tal dependência não necessita ser absoluta podendo ser parcial"(GOUVEIA, 2009).

Em outras palavras, além dos requisitos elencados no artigo 16, da Lei 8.213/91., que caracterizam o dependente previdenciário, os quais, pertencendo a segunda e terceira classe, devem comprovar a dependência economia entre ele e o segurado. Salvo os dependentes da primeira classe, que possuem submissão econômica presumida.

O artigo 16, também versa sobre a concorrência entre os dependentes: assim sendo, na existência de classe anterior exclui as classes posteriores. Logo, havendo dependentes da classe I, não haverá a concessão de benefícios para dependentes de classes II e III. E cessada a pensão do dependente da classe anterior, o benefício não será pago para o da classe posterior.

Bem como aponta Marcelo Tavares referente à concorrência entre os dependentes para a partilha de pensão por morte e auxílio reclusão.

"A existência de dependentes na classe anterior exclui os da posterior; sendo assim, por exemplo, se o cônjuge fazer jus a benefício, os pais do 
segurado não terão direito a ele, tampouco os irmãos. Cessada a pensão do dependente da classe anterior, o benefício não é pago para o da classe posterior.

Concorrem, em igualdade de condições, os dependentes da mesma classe. Por exemplo, havendo cônjuge e filho do segurado, a pensão será dividida em duas partes iguais. Cessada a quota-parte daquele cujo direito ao benefício cessar, haverá a redução da pensão em $10 \%$ e o rateio do valor entre os demais dependentes".(TAVARES, p. 89, 2015)

Assim sendo, primeiro deve se observar a existência de dependentes da primeira classe, pois, esses têm a preferência quanto às demais classes. Caso não haja dependentes da primeira classe, verificam-se a existência de dependentes da segunda classe e o requisito de dependência econômica com o segurado. Somente caso não exista dependentes da primeira e segunda classe é que os dependentes da terceira classe podem requerer sua habilitação como dependentes comprovando a submissão econômica com o segurado. Os dependentes da mesma classe concorrem em iguais condições. E cessada a quota parte de um dos dependentes, haverá redução da pensão em dez por cento e o rateio do valor restante entre os demais dependentes.

\section{SITUAÇÃO DE UNIÃO ESTÁVEL}

Dos dependentes da primeira classe o mais difícil de provar a qualidade de dependência previdenciária é a situação de companheiro ou companheira. Pois, estes necessitam comprovar a união estável com o segurado. Diferente do cônjuge, o companheiro não tem sociedade conjugal com o segurado.

Assim, leciona Tavares, quanto à definição de companheiro:

"Companheiro é o que, sem ser casado, mantém união estável como segurado, de acordo com o $\S 3$ do art. 226 da Constituição Federal. Perde a qualidade de dependente pela cessação da união estável com 
o segurado enquanto não lhe for garantida a prestação de alimentos".(TAVARES, p.91, 2015)

Outra descrição de companheiro é apresentada por Fabio Camacho Dell' Amore Torres (2012), que conceitua companheiro como sendo o dependente que não estava casado com o segurado:

"Considera-se companheiro ou companheira a pessoa que, sem ser casada, mantém união estável com o segurado ou com a segurada, entendendo-se por união estável a relação pública, contínua e duradoura estabelecida com a intenção de constituir família, devendo a lei facilitar a conversão da união estável em casamento. O Código Civil não admite a união estável se um dos companheiros já for casado"(TORRES, 2012).

Torres aponta também, que a legislação Civil não permite a união estável do segurado já casado. Logo, a união estável não é um instrumento de legalização da bigamia ou do poliamor, assuntos que não são abordados neste artigo.

Castro e Lazzari, também explicam a união estável conforme carta magma:

"É considerada união estável aquela verificada entre duas pessoas como entidade familiar, quando forem solteiros, separados judicialmente, divorciados ou viúvos, art. 226, § 3ำ, da Constituição Federal, desde que não haja impedimento para o casamento para ambas. A União Estável foi regulamentada pela Lei $n^{\circ}$ 9.278/96”.(CASTRO, C. A. P.; LAZZARI, J. B., p 155, 2017)

A constituição federal, em seu artigo 226, assim reconhece a união estável "§ $3^{\circ}$ - Para efeito da proteção do Estado, é reconhecida a união estável entre o homem e a mulher como entidade familiar, devendo a lei facilitar sua conversão em casamento". Reconhece também por analogia a situação de união estável entre casais homossexuais. 
Decreto $n^{\circ}$ 3.048/99, que regulamenta a Previdência Social também delibera sobre a união estável em seu artigo 16, I e $§$ 6:

"Art. 16. São beneficiários do Regime Geral de Previdência Social, na condição de dependentes do segurado: I - o cônjuge, a companheira, o companheiro e o filho não emancipado de qualquer condição, menor de vinte e um anos ou inválido; (...) §6 Considera-se união estável aquela configurada na convivência pública, contínua e duradoura entre o homem e a mulher, estabelecida com intenção de constituição de família, observado o $§ 10$ do art. 1.723 do Código Civil, instituído pela Lei no 10.406, de 10 de janeiro de 2002".

Logo, a união estável é aquela verificada entre duas pessoas, independente de gênero, como entidade familiar, quando forem solteiros, separados judicialmente, divorciados ou viúvos, desde que não haja impedimento legal para o casamento de ambos.

Para a devida comprovação do vínculo familiar e dependência econômica entre o companheiro e o segurado. O dependente deve apresentar no mínimo três documentos do rol apresentado no artigo 22, parágrafo terceiro, do Decreto 3.048/99.

"§3 Para comprovação do vínculo e da dependência econômica, conforme o caso, devem ser apresentados no mínimo três dos seguintes documentos:

I - certidão de nascimento de filho havido em comum;

II - certidão de casamento religioso;

III- declaração do imposto de renda do segurado, em que conste o interessado como seu dependente;

IV - disposições testamentárias;

VI - declaração especial feita perante tabelião; 
VII - prova de mesmo domicílio;

VIII - prova de encargos domésticos evidentes e existência de sociedade ou comunhão nos atos da vida civil;

IX - procuração ou fiança reciprocamente outorgada;

X - conta bancária conjunta;

$X I$ - registro em associação de qualquer natureza, onde conste o interessado como dependente do segurado;

XII - anotação constante de ficha ou livro de registro de empregados;

XIII- apólice de seguro da qual conste o segurado como instituidor do seguro e a pessoa interessada como sua beneficiária;

XIV - ficha de tratamento em instituição de assistência médica, da qual conste o segurado como responsável;

$X V$ - escritura de compra e venda de imóvel pelo segurado em nome de dependente;

$X V I$ - declaração de não emancipação do dependente menor de vinte e um anos; ou XVII - quaisquer outros que possam levar à convicção do fato a comprovar".

Deste modo, os documentos acima arrolados servem para comprovar a existência da união estável e não a dependência econômica, pois, ocorre a presunção legal da relação econômica entre o segurado e seu companheiro. Há também a possibilidade de produzir prova testemunhal por meio da Justificação administrativa. Nessa lógica, será preciso apresentar prova documental contemporânea à época dos fatos.

Nesse sentido o TNU editou a Súmula nํ6: "a comprovação de união estável para efeitos de concessão de pensão por morte prescinde de início de prova material". 
Nesse seguimento, a prova exclusivamente testemunhal para comprovação da união estável deve ser coerente e robusta. Logo, somente a prova testemunhal não serve como requisito objetivo para a concessão do benefício.

Assim fica claro que para comprovar a união estável, a dependência poderá ser evidenciada por qualquer meio de prova, inclusive a testemunhal. Que poderá ser requerida tanto por meio de justificação administrativo como por meio de uma ação judicial. Em ambos os casos, devem estar presente os requisitos subjetivos que caracterizam a união estável. E mesmo após a negativa do INSS, o dependente pode requerer por meio da ação judicial, para discutir a questão.

\section{APLICAÇÃO DA MP № 871/2019 EM RELAÇÃO À UNIÃO ESTÁVEL}

A Medida Provisória № 871 de 18 de janeiro de 2019, apresentou em seu artigo 25, a alteração da Lei oㅜ 8.213/91, no artigo 16, inserindo o parágrafo quinto:

$\S 5^{\circ}$, "A prova de união estável e de dependência econômica exigem inicio de prova material contemporânea dos fatos, não admitida a prova exclusivamente testemunhal, exceto na ocorrência de motivo de força maior e ou caso fortuito, conforme disposto no Regulamento".

Apesar da alteração apresentada pela MP 871/19 seguir o entendimento da Turma Nacional de Uniformização dos Juizados Especiais Federais. Consolidado na Súmula 63.

Todavia, mesmo nos dias atuais, com o instituto da união estável sendo amplamente reconhecido pelo ordenamento jurídico brasileiro. No âmbito previdenciário, quando se trata de requere benefício previdenciário, a exigência de prova documental que ateste a existência da união estável se mostra dificultosa para os dependentes.

Pois, a grande maioria dos dependentes por união estável, não são pessoas esclarecidas, jovens, de formação superior, com saúde. Em regra, o requerente, ao benefício são pessoas idosas, de baixa renda, enfermas, com dificuldades de 
locomoção, vivendo uma morte social, que perdeu seu companheiro também idoso. $\mathrm{E}$ ao se dirigir a uma agência do INSS, tem seu benefício negado, por falta de provas.

Pois a definição legal previdenciária exige como requisitos fundamentais para caracterizar a existência da união estável, com convivência duradoura, pública e continua, e com o objetivo de constituir família. Logo a produção de prova se dá por meio de prova material e testemunhal.

Desse modo, a complexidade de produção de prova, havendo somente prova testemunhal que demonstre a existência da união estável até a data do óbito, o beneficiário, é obrigado a buscar as vias judiciais para requerer o seu direito.

À vista disso, é o entendimento jurisprudencial:

PREVIDENCIÁRIO. PRELIMINAR DE CERCEAMENTO DE DEFESA REJEITADA. PENSÃO POR MORTE. L. 8.213/91, ART 74. COMPANHEIRA. DEPENDÊNCIA ECONÔMICA. UNIÃO ESTÁVEL NÃO COMPROVADA. APELAÇÃO DO INSS PROVIDA. TUTELA REVOGADA. DESNECESSIDADE DE DEVOLUÇÃO DE VALORES. Quanto à alegação de cerceamento de defesa, ante a não produção de provas, esclareça-se que cabe ao Magistrado, no uso do seu poder instrutório, deferir ou não, determinada prova, de acordo com a necessidade, para a formação do seu convencimento, nos termos do art. 370 do novo CPC - Mesmo que assim não fosse, em regra, a prova compete ao autor e a contraprova ao réu. Assim, ao INSS caberia buscar os esclarecimentos necessários junto aos órgãos indicados, sendo lícita a atuação do Judiciário em casos extremos, quando demonstrada a impossibilidade de diretamente o fazê-lo - Para a concessão da pensão por morte é necessária a comprovação da condição de segurado do de cujus e a dependência econômica da parte autora - A ocorrência do evento morte, em 01/02/2012, encontra-se devidamente comprovada pela certidão de óbito - A qualidade de segurado do falecido na data do passamento restou demonstrada, nos termos do artigo 15, II, da Lei $\mathrm{n}$. 
8.213/91 - Todavia, no caso, da análise dos documentos apresentados não se infere a existência da aludida união estável - Não há um único documento contemporâneo á época do passamento que estabeleça um liame entre a autora e o falecido, conforme pretendido - As declarações acostadas aos autos, noticiando a existência de união estável, equivalem a meros depoimentos reduzidos a termo, sem o crivo do contraditório, conforme entendimento já pacificado no âmbito desta Corte - As fotografias nada permitem concluir quanto às pessoas, períodos e circunstâncias nela retratados - A ficha cadastral do CNIS, em nome da autora e do falecido, a despeito de apontar domicílio em comum, não the aproveita, pois se trata de documento particular, passível de alteração a qualquer momento -Há que se diferenciar relacionamento amoroso de união estável. Não é crível que um casal que desfrute de vida em comum, com animus de tornar a relação definitiva, não tivesse um único comprovante de domicílio em comum, de encargos financeiros compartilhados, de registro em associação de qualquer natureza, ou de outros documentos arrolados no artigo 22 do Decreto 3.048/99 - À míngua do início de prova material, a prova testemunhal, não se mostrou suficientemente robusta a comprovar a união estável - Apelação do INSS provida - Sentença reformada. Tutela revogada. Dispensada a devolução de valores.

(TRF-3 - Ap: 00176854420184039999 SP, Relator: DESEMBARGADOR FEDERAL DAVID DANTAS, Data de Julgamento: 10/09/2018, OITAVA TURMA, Data de Publicação: e-DJF3 Judicial 1 DATA:24/09/2018)

AGRAVO EM RECURSO ESPECIAL № 749.016 - SP (2015/01793331) RELATOR : MINISTRO NAPOLEÃO NUNES MAIA FILHO AGRAVANTE : MARIA DE LOURDES DA SILVA ADVOGADO : CELSO MASCHIO RODRIGUES E OUTRO (S) - SP099035 AGRAVADO : INSTITUTO NACIONAL DO SEGURO SOCIAL DECISÃO PREVIDENCIÁRIO. AGRAVO EM RECURSO ESPECIAL. PENSÃO 
POR MORTE. POSSIBILIDADE DE RECONHECIMENTO DE UNIÃO ESTÁVEL. AMPARADO EM PROVA EXCLUSIVAMENTE TESTEMUNHAL, AUSÊNCIA DE DISPOSIÇÃO LEGAL EM SENTIDO CONTRÁRIO. COMPANHEIRO NÃO PRECISA COMPROVAR DEPENDÊNCIA ECONÔMICA. NADA SENDO DADO AO INTÉRPRETE ACRESCER O REQUISITO DA DEPENDÊNCIA ECONÔMICA, QUE DEVE SER PRESUMIDA. CONCLUSÃO DA CORTE DE ORIGEM QUE DESTOA DO ENTENDIMENTO CONSOLIDADO ACERCA DA MATÉRIA. AGRAVO CONHECIDO PARA DAR PROVIMENTO AO RECURSO ESPECIAL, RESTAURANDO A SENTENÇA. 1. Agrava-se de decisão que negou seguimento a Recurso Especial de MARIA DE LOURDES DA SILVA, interposto com fundamento nas alíneas a e c do art. 105 III da Constituição Federal, no qual se insurge contra acórdão proferido pelo Tribunal Regional Federal da 3a. Região, assim ementado: PREVIDENCIÁRIO. PROCESSUAL CIVIL. EMBARGOS DE DECLARAÇÃO RECEBIDOS COMO AGRAVO. DECISÃO MONOCRÁTICA. AUSÊNCIA DE ILEGALIDADE OU ABUSO DE PODER. PENSÃO POR MORTE. REDISCUSSÃO DE MATÉRIA JÁ DECIDIDA. O art. 557 do Código de Processo Civil consagra a possibilidade de o recurso ser julgado pelo respectivo Relator. Segundo entendimento firmado nesta Corte, a decisão do relator não deve ser alterada quando fundamentada e nela não se vislumbrar ilegalidade ou abuso de poder que resulte em dano irreparável ou de difícil reparação para a parte. A decisão agravada abordou todas as questões suscitadas e orientou-se pelo entendimento jurisprudencial dominante. Pretende o agravante, em sede de agravo, rediscutir argumentos já enfrentados pela decisão recorrida. Recebimento dos embargos como agravo. Agravo desprovido. Decisão mantida. 2. Nas razões do Recurso Especial inadmitido, além da divergência jurisprudencial, a recorrente defende seu direito à percepção do benefício, ao argumento de que restou devidamente comprovada a sua condição de companheira do segurado 
instituidor da pensão. 3. É o relatório. Decido. 4. O que se verifica da leitura dos autos é que a Corte de origem pautou o indeferimento da pensão ao argumento de que não restou comprovada a dependência econômica da companheira do Segurado, instituidor da pensão. 5. Cabe trazer à lume o seguinte trecho do acórdão recorrido: À f. 69, consta que a autora foi inscrita como dependente, na CTPS do de cujus. No entanto, no presente caso não se pode identificar a dependência econômica da autora em relação ao falecido. Com efeito, a concessão de benefício de pensão por morte no caso não encontra amparo no sistema previdenciário, já que motivado por um fato gerador ocorrido em 1983, ou seja, 24 (vinte e quatro) anos antes da propositura desta ação. Nesse intervalo de tempo, a autora sobreviveu de outros meios e possivelmente teve outros relacionamentos. Lícito é concluir que a autora não é dependente do falecido há mais de 2 (duas) décadas, de modo que qualquer presunção formal de dependência econômica cai por terra. 6 . Tal fundamento, contudo, não encontra qualquer ampara no ordenamento jurídico. 7. De fato, a dependência econômica da companheira é presumida, por força do art. 16 da Lei 8.213/1991, a necessária dependência econômica para a concessão da pensão por morte entre companheiros de união estável é presumida. 8. Ademais, acerca da matéria, esta Corte consolidou a orientação de que a legislação previdenciária não exige início de prova material para a comprovação de união estável, para fins de concessão de benefício de pensão por morte, sendo bastante, para tanto, a prova testemunhal, uma vez que não cabe ao julgados criar restrições quando o legislador assim não o fez. A propósito, os seguintes julgados: PROCESSO CIVIL. AGRAVO INTERNO EM RECURSO ESPECIAL. DECISÃO UNIPESSOAL FUNDADA NA INCIDÊNCIA DA SÚMULA 7/STJ. ARGUMENTAÇÃO DE QUE SE TRATARIA DE QUESTÃO RELACIONADA A NECESSIDADE DE CONFIRMAÇÃO DA PROVA TESTEMUNHAL PELA DOCUMENTAL. MATÉRIA DISTINTA DA EXAMINADA. PREVALÊNCIA DA VERSÃO DOS FATOS E DAS 
PROVAS DA PARTE ADVERSA. 1. No âmbito do recurso especial, não se pode apurar a presença dos requisitos configuradores da união estável, especialmente quando, examinada a prova testemunhal, o órgão julgador se convence da verossimilhança de outra versão dos fatos, sustentada em outros meios de prova igualmente idôneos. Incidência da Súmula 7/STJ. 2. Agravo desprovido (Aglnt no REsp. 1.658.164/RS, Rel. Min. NANCY ANDRIGHI, DJe 28.5.2018). 22 PROCESSUAL CIVIL. AGRAVO REGIMENTAL NO RECURSO ESPECIAL. SERVIDOR PÚBLICO FEDERAL. PENSÃO POR MORTE. COMPANHEIRO. UNIÃO ESTÁVEL. ACÓRDÃO RECORRIDO QUE ENTENDE PELA NÃO COMPROVAÇÃO DA UNIÃO ESTÁVEL ATÉ O EVENTO MORTE. DESCONSIDERAÇÃO DE PROVA TESTEMUNHAL CITADA NO PRÓPRIO ACÓRDÃO REGIONAL. IMPOSSIBILIDADE. INEXISTÊNCIA DE HIERARQUIA ENTRE OS MEIOS DE PROVA. REVALORAÇÃO DA PROVA. POSSIBILIDADE. AFRONTA AO PRINCÍPIO DA INEXISTÊNCIA DE HIERARQUIA ENTRE OS MEIOS DE PROVA. ADMISSIBILIDADE DA PROVA TESTEMUNHAL PARA COMPROVAÇÃO DE UNIÃO ESTÁVEL. AGRAVO REGIMENTAL NÃO PROVIDO. 1. Tendo o Tribunal de origem reconhecido a existência da relação more uxória entre o agravado e a de cujus no período de junho de 1999 a junho de 2003, contudo, rejeitado a pretensão autoral, por entender inexistir nos autos prova documental que demonstre de forma inequívoca que o relacionamento havido tenha perdurado até a data do óbito da servidora - o que ocorreu em 2005, tais como "como notas de pagamento de despesas comuns ao casal, correspondências, conta bancária conjunta, cartas, bilhetes, cartões, etc, o que é relativamente comum num relacionamento longo" , - a despeito do próprio Tribunal desconsiderar a prova testemunhal produzida nesse sentido, sob o fundamento de que "seu valor probatório seria mínimo, em virtude da ausência de outras provas materiais convincentes neste sentido" (fl. 198e), não há que se falar em reexame do conjunto fático-probatório, a afastar o óbice da Súmula 7/STJ, mas efetivamente em revaloração das 
provas regularmente examinadas pelo Tribunal de origem, pois o que se discute é se a prova testemunhal é ou não suficiente a comprovação de união estável. 2. O Tribunal de origem ao exigir a produção de prova documental para a comprovação da união estável no período que antecedeu o óbito da ex-servidora, desconsiderando valor probatório das provas testemunhais produzidas, está por violar o próprio princípio da inexistência de hierarquia das provas. 3. Agravo regimental não provido (AgRg no REsp. 1.536.974/RJ, Rel. Min. MAURO CAMPBELL MARQUES, DJe 18.12.2015). 9. Impõe-se, assim, a reforma do acórdão recorrido que desconsiderou as provas materiais e o teor dos testemunhos coletados, afastando a decisão do juízo sentenciante que presidiu a instrução do feito, bem valorando as provas ao ter estabelecido contado direto com as partes, encontrando-se em melhor condição de aferir a realidade dos autos. A propósito, os seguintes julgados: ADMINISTRATIVO. AGRAVO REGIMENTAL NO AGRAVO EM RECURSO ESPECIAL. SERVIDOR PÚBLICO. DIREITO À PENSÃO. UNIÃO ESTÁVEL. COMPROVAÇÃO DE DEPENDÊNCIA ECONÔMICA. DESNECESSIDADE. VIOLAÇÃO AO ART. 535 DO CPC. OMISSÃO. INEXISTÊNCIA. REPERCUSSÃO GERAL. POSSIBILIDADE. DISPOSITIVOS CONSTITUCIONAIS. COMPETÊNCIA DO STF. SOBRESTAMENTO DO FEITO. DESNECESSIDADE. 1. Verifica-se não ter ocorrido ofensa ao art. 535 do CPC, na medida em que o Tribunal de origem dirimiu, fundamentadamente, as questões que the foram submetidas, apreciando integralmente a controvérsia posta nos presentes autos. 2. Comprovada a união estável, a dependência econômica é presumida. Precedentes: REsp 1.376.978/RJ, Rel. Ministro Ari Pargendler, Primeira Turma, julgado em 21/05/13, DJe 4/6/2013 e REsp 614.191/RS, Rel. Ministro Paulo Gallotti, Sexta Turma, julgado em 28/09/2004, DJe 13/03/2006. 3. Não cabe ao Superior Tribunal de Justiça, ainda que para fins de prequestionamento, examinar na via especial matéria constitucional, sob pena de usurpação da competência do Supremo 
Tribunal Federal. 4. A repercussão geral reconhecida pela Suprema Corte, nos termos do art. 543-B do CPC, não enseja o sobrestamento dos recursos especiais que tramitam neste Superior Tribunal de Justiça. Nesse sentido: AgRg no REsp 1.344.073/RS, Rel. Ministro Arnaldo Esteves Lima, Primeira Turma, DJe 06/09/2013; e AgRg no AREsp 244.747/SP, Rel. Ministro Castro Meira, Segunda Turma, DJe 08/02/2013. 5. Agravo regimental a que se nega provimento (AgRg no AREsp. 391.737/RS, Rel. Min. SÉRGIO KUKINA, DJe 12.5.2015). 222 PREVIDENCIÁRIO. PENSÃO POR MORTE DE SERVIDOR CIVIL. COMPANHEIRA. COMPROVAÇÃO DE DEPENDÊNCIA ECONÔMICA. DESNECESSIDADE. A teor do art. 217, I, c, da Lei ํo 8.112, de 1990, são beneficiários das pensões "o companheiro ou companheira designado que comprove união estável como entidade familiar". A norma não exige a prova de dependência econômica em relação ao de cujus. Recurso especial conhecido e provido (REsp. 1.376.978/RJ, Rel. Min. ARI PARGENDLER, DJe 4.6.2013). 10. Ante o exposto, conheço do Agravo para dar provimento ao Recurso Especial de MARIA DE LOURDES DA SILVA, restaurando a sentença. 11. Publique-se. 12. Intimações necessárias. Brasília (DF), 18 de setembro de 2018. NAPOLEÃO NUNES MAIA FILHO MINISTRO RELATOR

(STJ - AREsp: 749016 SP 2015/0179333-1, Relator: Ministro NAPOLEÃO NUNES MAIA FILHO, Data de Publicação: DJ 27/09/2018)

Nos julgados acima observa-se que na primeira lide, o dependente juntou aos autos fotos, testemunhas, ficha cadastral do CNIS comprovando o mesmo endereço. Porém não foi suficiente para a comprovação da união estável.

Nesse outro recurso observa-se que a autora juntou a CTPS do segurado, onde constava a inscrita como sua dependente e não restou provado a união estável. Nesse sentido, não são raras as vezes que diante da dificuldade de comprovar o vínculo familiar com provas documentais, aos companheiros se impede o gozo do benefício da pensão por morte. 
Para o instituto previdenciário a declaração de união estável em pactos particulares ou público, muitas vezes reconhecido em Cartório de Títulos e Documentos. Tais contrato ou declarações escritas, não servem como prova inequívoca da existência da união estável.

\section{CONCLUSÃO}

Diante desta dificuldade de comprovar a situação da união estável frente ao Direito Previdenciário. Tendo justamente a necessidade de provar a publicidade e o objetivo de constituição de família, como obstáculo para a concessão do benefício. Pois. Como requisitos legais previstos na legislação previdenciária. Faz necessário comprovar três provas mínimas, administrativamente a situação de dependência econômica, conforme estipula o art. 22, § 3o, do Decreto 3.048/99. É possível apresentar prova testemunhal, por meio da justificação administrativa ou Ação Judicial através de advoga especializado em matéria previdenciária. A negativa administrativa do benefício frente a Previdência Social possibilita o ajuizamento da ação perante o Poder Judiciário.

O objetivo desse artigo científico é demonstrar a alteração implantada pela MP $871 / 2019$, em seu art. 25, que inclui o parágrafo $5^{\circ}$, no artigo 16 , da Lei 8.213/91, bem como a dificuldade da concessão do benefício para companheiros em situação de união estável. Logo casais que convivem em situação de união estável devem buscar fazer provas de constituição familiar, elementos que uma entidade família possui cotidianamente, comprovantes de endereços em nome dos conviventes, contratos de compra de bens em mesmo endereço e em nome de ambos, declaração em cartório de união estável, conta conjunta em instituição financeira, declaração de imposto de renda constando como dependente, anotação na CTPS com dependente do segurado, são exemplos de provas mínimas para a comprovação da união estável. Visto que, comprovantes de pagamento do consumo de água, luz, telefone, internet e impostos não possuem a comprovação, não caracterizam a situação da união estável.

Assim sendo, na prática, há a necessidade de um número maior que três de indícios de prova material, documental, para comprovar a união estável, perante a Previdência 
Social. Nesse viés, as famílias em união estável devem precaver-se, antecipando a produção de provas e indícios de provas, com a finalidade de garantir a um dos conviventes o direito ao benéfico previdenciário da pensão por morte.

\section{REFERÊNCIAS}

CASTRO, C. A. P.; LAZZARI, J. B., Manual de Direito Previdenciário, 20ª ed., Rio de Janeiro: Editora Forense Ltda., 2017.

Conselho da Justiça Federal (Brasil). Turma Nacional de Uniformização dos Juizados Especiais Federais. Comentários às súmulas da Turma Nacional de Uniformização dos Juizados Especiais Federais / Conselho da Justiça Federal, Turma Nacional de Uniformização dos Juizados Especiais Federais ; coordenador: Frederico Augusto Leopoldino Koehler ; [autores] Alcides Saldanha Lima ... [et al.]. - Brasília : Conselho da Justiça Federal, Centro de Estudos Judiciários, 2016.

GOUVEIA, Carlos Alberto Vieira de. Os dependentes e os principais aspectos na concessão dos benefícios previdenciários. In: Âmbito Jurídico, Rio Grande, XII, n. 66, jul 2009. Disponível em: <http://www.ambitojuridico.com.br/site/index.php?n_link=revista_artigos_leitura\&artigo_id=6196>. Acesso em 14 fev 2019.

IBGE - Instituto Brasileiro de Geografia e Estatística. Relações entre as Alterações Históricas na Dinâmica Demográfica Brasileira e os Impactos Decorrentes do Processo de Envelhecimento da População. Rio de Janeiro, 2016. Disponível em:<https://biblioteca.ibge.gov.br/visualizacao/livros/liv98579.pdf>. Acesso em $03 \mathrm{fev}$ 2019.

TAVARES, M. L., Direito Previdenciário: Regime Geral de Previdência Social e Regras Constitucionais dos Regimes Próprios de Previdência Social, 16ª Ed., Niterói: Editora Impetus, 2015. 
TORRES, Fabio Camacho Dell' Amore. Os Dependentes dos Segurados da Previdência Social. Conteudo Juridico, Brasilia-DF: 07 fev. 2012. Disponivel em: <http://www.conteudojuridico.com.br/?artigos\&ver=2.35740\&seo=1>. Acesso em: 14 Enviado: Fevereiro, 2019.

Aprovado: Julho, 2019. 